\title{
Pitfalls and feedback when constructing topological pressure- temperature phase diagrams
}

\author{
R. Ceolin ${ }^{1,2}$, S. Toscani ${ }^{1,3}$, Ivo B. Rietveld ${ }^{1}$, M. Barrio ${ }^{2}$, J. Ll. Tamarit ${ }^{2 *}$ \\ ${ }^{1}$ Laboratoire de Chimie Physique et Chimie Minérale, Faculté de Pharmacie, Université Paris \\ Descartes, 4 avenue de l'observatoire, 75006 Paris, France \\ ${ }^{2}$ Grup de Caracterització de Materials (GCM), Departament de Física i Enginyeria Nuclear, \\ Universitat Politècnica de Catalunya, Diagonal 647, 08028 Barcelona, Catalunya, Spain \\ ${ }^{3}$ Département de Chimie - UMR 6226, Faculté des Sciences, Université de Rennes 1, \\ Bâtiment 10B, 263, Avenue du Général Leclerc, 35042 Rennes Cedex, France
}

*corresponding author: josep.lluis.tamarit@upc.edu

\begin{abstract}
The stability hierarchy between different phases of a chemical compound can be accurately reproduced in a topological phase diagram. This type of phase diagrams may appear to be the result of simple extrapolations, however, experimental complications quickly increase in the case of crystalline trimorphism (and higher order polymorphism). To ensure the accurate positioning of stable phase domains, a topological phase diagram needs to be consistent. This paper gives an example of how thermodynamic feedback can be used in the topological construction of phase diagrams to ensure overall consistency in a phase diagram based on the case of piracetam crystalline trimorphism.
\end{abstract}




\section{Introduction}

In a recent article, a pressure-temperature phase diagrams for the trimorphism of piracetam has been obtained through a topological approach [1]. An annotated version of the stable pressure-temperature (P-T) phase diagram proposed in Figure 4 of reference [1] is provided here in Figure 1. It appears that the final phase diagram of the quoted article is not in accordance with the data reported therein. For topological constructions of phase diagrams, feedback systems can be used, which can help identify and avoid inconsistencies, even if the process of constructing phase diagrams can be complicated. In the present paper, an example will be given of how inconsistencies in a topological phase diagram can be identified.

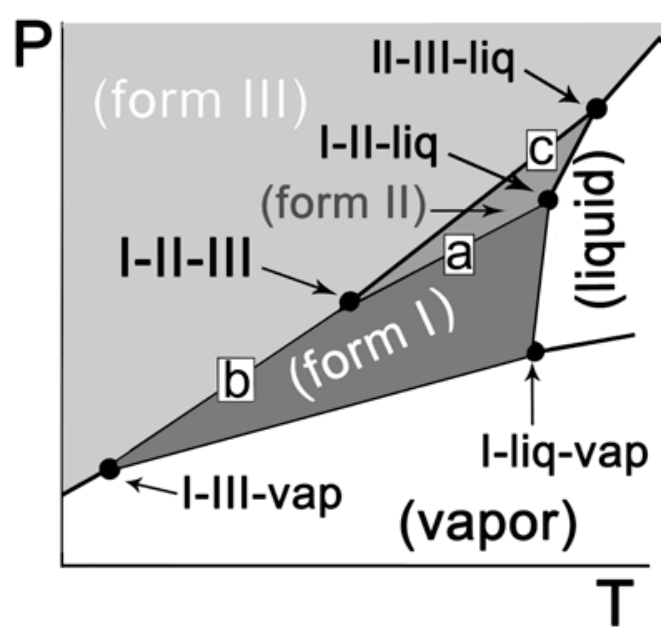

Figure 1. Annotated version of the topological pressure-temperature phase diagram presented in Figure 4 of reference [1]. The stable phase regions for forms I, II, and III, are indicated in accordance with ref. [1] as are the two-phase equilibria with line a: I-II, line b: I-III, and line c: II-III and the resulting triple points.

The construction of the topological phase diagram depicted in Figure 1 was based on experimental differential scanning calorimetry (DSC) and X-ray diffraction data reported in the Tables 3, 4, and 7 of reference [1]. In addition, the temperature and enthalpy change of the transition II $\rightarrow$ liq was provided in the text in reference [1]. These data have been summarized in Table 1 in the present paper. For the solid-solid transition between forms III and II, neither the transition enthalpy nor the transition temperature were reported in the original publication; however, according to Figure 1, $T_{\mathrm{III} \rightarrow \mathrm{II}}$ should be higher than $T_{\mathrm{III} \rightarrow \mathrm{I}}$ by simple extrapolation of the two-phase equilibrium II-III to the temperature axis $(\mathrm{P}=0)$. The II-III equilibrium has a steeper slope in Figure 1 than equilibrium III-I and the two equilibria cross at increased 
positive pressure, thus by deduction from Figure 1 the following transition temperature sequence can be obtained: $T_{\mathrm{II} \rightarrow \mathrm{I}}<T_{\mathrm{III} \rightarrow \mathrm{I}}<T_{\mathrm{III} \rightarrow \mathrm{II}}$.

The diagram in Figure 4 of reference [1] (here Figure 1) has been constructed using the alternation rule and the Clapeyron equation:

$$
\frac{d P}{d T}=\frac{\Delta S}{\Delta V}=\frac{\Delta H}{T \Delta V}
$$

with $\mathrm{d} P / \mathrm{d} T$ the slope of a two-phase equilibrium in the pressure-temperature phase diagram, $\Delta S$ the entropy change associated with the equilibrium, $\Delta V$ the volume change, $\Delta H$ the enthalpy change, and $T$ the temperature at which the two-phase equilibrium has been observed. The alternation rule, which is a direct result of the intersecting Gibbs-energy surfaces for the different phases, states that equilibria passing through a triple point will change their stability ranking with one level and it implies that the stability ranking of the phase equilibria around a triple point will alternate between two levels of stability [2].

For the topological construction of P-T phase diagrams, data obtained at ordinary pressure (i.e. pressure conditions in a closed DSC pan) are generally used in the Clapeyron equation and equilibrium lines are approximated by straight lines. In particular solid-solid equilibria are straight over extensive temperature and pressure ranges and using this approach in the correct way leads to reliable P-T phase diagrams, as was demonstrated in the case of paracetamol [3,4], benzocaine [10], adamantane derivatives [5-7] and other organic compounds [8-11]. The inequalities between the slopes of the different equilibria can be determined once the respective enthalpy changes, volume changes, and equilibrium temperatures have been determined. Making use of the alternation rule, the stability ranking of the different equilibria in the phase diagram can be determined. For trimorphism, this has been demonstrated for ferrocene by two of the present authors in 2002 [12]. 
Table 1. Data from the text and from Tables 4 and 7 in reference [1] for the phase transitions of the three most prevalent forms of piracetam

\begin{tabular}{|c|c|c|c|c|c|c|}
\hline Transition & $\begin{array}{c}\mathrm{T}^{\mathrm{a}} \\
{ }^{\circ} \mathrm{C}\end{array}$ & $\begin{array}{l}T^{\mathbf{b}} \\
/ \mathbf{K}\end{array}$ & $\begin{array}{l}\Delta \boldsymbol{H}^{\mathbf{a}} \\
/ \mathbf{J} \mathbf{g}^{-1}\end{array}$ & $\begin{array}{c}\Delta V^{\mathrm{f}} \\
/ \mathrm{cm}^{3} \mathrm{~mol}^{-1}\end{array}$ & $\begin{array}{c}\Delta V^{\mathrm{g}} \\
/ \mathrm{cm}^{3} \mathrm{~g}^{-1}\end{array}$ & $\begin{array}{l}(\mathrm{dP} / \mathrm{dT})^{\mathrm{h}} \\
/ \mathrm{MPa} \mathrm{K}^{-1}\end{array}$ \\
\hline $\mathrm{II} \rightarrow \mathrm{I}$ & $\begin{array}{c}91.9^{\mathrm{c}} \\
87^{\mathrm{d}}\end{array}$ & $\begin{array}{l}365 \\
360\end{array}$ & $\begin{array}{c}24.8 \\
-\end{array}$ & $\begin{array}{c}- \\
4.71\end{array}$ & $\begin{array}{c}- \\
0.0331\end{array}$ & 2.08 \\
\hline $\mathrm{III} \rightarrow \mathrm{I}$ & $\begin{array}{c}100.9^{\mathrm{c}} \\
97^{\mathrm{d}}\end{array}$ & $\begin{array}{l}374 \\
370\end{array}$ & $\begin{array}{c}26.8 \\
-\end{array}$ & $\begin{array}{c}- \\
6.18\end{array}$ & $\begin{array}{c}- \\
0.0435\end{array}$ & $\begin{array}{c}- \\
1.67\end{array}$ \\
\hline III $\rightarrow$ liq & $139.4^{\mathrm{C}}$ & 412.4 & 211.3 & 16.97 & 0.1194 & 4.29 \\
\hline $\mathrm{II} \rightarrow$ liq & $141.5^{\mathrm{e}}$ & 414.5 & $211.8^{\mathrm{e}}$ & 16.59 & 0.1167 & 4.38 \\
\hline $\mathrm{I} \rightarrow$ liq & $149.8^{\mathrm{C}}$ & 422.8 & 187 & 11.29 & 0.07942 & 5.57 \\
\hline
\end{tabular}

${ }^{\mathrm{a}}$ From Table 4 in reference [1].

${ }^{\mathrm{b}}$ The temperatures in kelvin have been obtained by adding 273 to the temperatures in degrees

Celsius as in Table 7 of reference [1].

${ }^{\mathrm{c}}$ By DSC as indicated in Table 4 of reference [1].

${ }^{\mathrm{d}}$ By X-ray diffraction as indicated in Table 4 of reference [1].

${ }^{\mathrm{e}} \mathrm{By}$ calculation, page 170 in [1]

${ }^{\mathrm{f}}$ From Table 7 in reference [1]

${ }^{\mathrm{g}}$ Calculated by dividing the values in the fifth column by the molar weight of piracetam $142.156 \mathrm{~g} \mathrm{~mol}^{-1}$.

${ }^{\mathrm{h}}$ From Table 7 in reference [1], and verified by applying equation 1 .

\section{On the interpretation of the calorimetric data}

The topological construction of P-T phase diagrams depends for a large part on the interpretation of data obtained by DSC and X-ray diffraction under ordinary conditions. Thus, the applied data will be considered before discussing the actual construction of the phase diagram. Concerning the DSC results, it is mentioned on page 168 of the paper of reference [1]: "Randomly, for some experiments carried out by DSC on Form III at $10^{\circ} \mathrm{C} \mathrm{min}^{-1}$, we get a transformation of Form III at a higher temperature, i.e. $127.5{ }^{\circ} \mathrm{C}$ (figure 1, curve b). This could not be ascribed to a transformation into Form I, the latter occurring at a lower temperature. We therefore hypothesized that this transformation could be the Form III toward Form II transformation, followed by the melting of Form II and recrystallization into Form I."

The hypothesis is incorrect for several reasons. Firstly, no enthalpy data are provided for the transition discussed in the citation above, which presumably is from form III to form 
II. Using a Hess cycle and starting from form III, it is a thermodynamic fact that $\Delta H_{\mathrm{III} \rightarrow \mathrm{I}}+$ $\Delta H_{\mathrm{I} \rightarrow \mathrm{II}}+\Delta H_{\mathrm{II} \rightarrow \mathrm{III}}=0$ and thus that $\Delta H_{\mathrm{III} \rightarrow \mathrm{II}}=\Delta H_{\mathrm{III} \rightarrow \mathrm{I}}+\Delta H_{\mathrm{I} \rightarrow \mathrm{II}}$ (The direction of the transition $\mathrm{II} \rightarrow \mathrm{III}$ or III $\rightarrow$ II defines the sign of the enthalpy change). Thus with the data in Table 1, one finds $\Delta H_{\mathrm{III} \rightarrow \mathrm{II}}=26.8-24.8=2 \mathrm{~J} \mathrm{~g}^{-1}$. It implies that the peak for the $\Delta H_{\mathrm{III} \rightarrow \text { II }}$ must be very small in relation to those of the two other solid-solid transitions. Considering curve ' $b$ ' in Figure 1 in reference [1] (see the annotated Figure A.1 in the Appendix of the present paper), it can be seen that the peak is actually of the same magnitude as the solid-solid transitions observed in curve 'a' (III $\rightarrow \mathrm{I})$ and curve 'e' (II $\rightarrow \mathrm{I})$ (see Figure A.1 in the Appendix below). To verify the size of the peak in form ' $b$ ', the curves have been enlarged and the sizes of the three solid-solid peaks relative to the melting peak of form I, which in each curve is the form that melts, have been determined by weighing (see Appendix). Thus, if $\Delta H_{\mathrm{I} \rightarrow \text { liq }}=187 \mathrm{~J} \mathrm{~g}^{-1}$ (taken as $100 \%$ ), a relative peak size of $15 \%$ in curve 'a' for $\Delta H_{\text {III } \rightarrow \mathrm{I}}$ equals $28 \mathrm{~J} \mathrm{~g}^{-1}$ and a relative peak size of $12 \%$ in curve 'e' for $\Delta H_{\mathrm{II} \rightarrow \mathrm{I}}$ equals $22.4 \mathrm{~J} \mathrm{~g}^{-1}$. The enthalpy of the unknown transition, $\Delta H_{\mathrm{III} \rightarrow \mathrm{x}}$, has a relative surface of $15 \%$ and equals therefore $28 \mathrm{~J} \mathrm{~g} \mathrm{~g}^{-1}$; hence transition III $\rightarrow \mathrm{x}$ is most likely $\mathrm{III} \rightarrow \mathrm{I}$ and certainly cannot be $\mathrm{III} \rightarrow \mathrm{II}$ as it was originally assigned in reference [1], because the enthalpy represented by the peak in curve ' $b$ ' is far too large for the $\Delta H_{\mathrm{III} \rightarrow \mathrm{II}}=2 \mathrm{~J} \mathrm{~g}^{-1}$ of the III $\rightarrow$ II transition.

Secondly, once the solid-solid peak in curve 'b' in Figure 1 of reference [1] had been assigned to the III $\rightarrow$ II transition, it was assumed by the authors that the small endoexothermic effect observed a few degrees higher was the fusion of form II and recrystallization into form I, which then melts at its normal temperature. However, if form II melts and the melt turns into form I, the overall enthalpy will have to be equal to the transition enthalpy of II $\rightarrow$ I as in thermodynamics the path is not important, only the initial and the final state. Neglecting heat capacity differences, one would expect a positive enthalpy of about $24.8 \mathrm{~J} \mathrm{~g}^{-1}$ for the sum over the processes of melting and recrystallization. Determining the area of the endo-exo peak relative to the melting peak of form I, one finds a value of about $1 \%$, which is equal to an enthalpy of $1.9 \mathrm{~J} \mathrm{~g}^{-1}$. This cannot coincide with the proposed transitions of II $\rightarrow$ liq $\rightarrow$ I, because the enthalpy of the summed peaks is much too low.

A last point to be made is that with the data in Table 1, the slope of the III-II equilibrium can be calculated. The enthalpy change $\Delta H_{\mathrm{III} \rightarrow \text { II }}$ was found to be $2 \mathrm{~J} \mathrm{~g}^{-1}$. In the same way, by thermodynamic cycle, the volume change from III to II can be calculated as $\Delta V_{\mathrm{III} \rightarrow \mathrm{I}}+\Delta V_{\mathrm{I} \rightarrow \mathrm{II}}+\Delta V_{\mathrm{II} \rightarrow \mathrm{III}}=0$ and thus $\Delta V_{\mathrm{III} \rightarrow \mathrm{II}} \approx 0.0103 \mathrm{~cm}^{3} \mathrm{~g}^{-1}$ using the data in Table 1 (again it has to be kept in mind that the direction of the arrow defines the sign of the volume 
change). Using the enthalpy and volume changes together with the transition temperature of $\mathrm{III} \rightarrow \mathrm{II}$ of $400.5 \mathrm{~K}$ (127.5 ${ }^{\circ} \mathrm{C}$ as observed in reference [1]; see the quotation above), the slope of the equilibrium is found to be $0.48 \mathrm{MPa} \mathrm{K}^{-1}$, which is a shallower slope than those of the two other equilibria. This, however, is in contradiction with the proposed phase diagram in Figure 1, where equilibrium III-II has the steepest slope. One ought to conclude therefore that the phase diagram is inconsistent with the available data. This will be discussed in more detail below.

\section{3.- Construction of the P-T diagram using the data in Table 1}

Once the data obtained by DSC and X-ray diffraction has been verified, the subsequent step is tracing the equilibrium lines using the Clapeyron equation (1). At the intersections of the equilibrium lines, the positions of the triple points can be found, which make up the framework of a topological P-T phase diagram. In the case of trimorphism, the number of triple points in a phase diagram incorporating the liquid and the vapor phase amounts to 10 as established in 1890 by Riecke [13]. For reference, the P-T phase diagram containing all 10 triple points provided in Figure 3 of reference [1], has been reproduced in Figure 2A. In Figure 2B, the phase diagram is provided that is based on the data in Table 1 and constructed in accordance with thermodynamics.

\section{1.- Triple points I-II-liq, I-III- liq and II-III-liq}

The three triple points I-II-liq, I-III-liq, and II-III-liq have the liquid phase in common implying that two melting equilibria and one solid-solid equilibrium intersect each other in each of the triple points. As stated in the introduction, two-phase equilibria can be safely considered straight over a considerable pressure and temperature range. Thus, using the Clapeyron equation and starting at the measured or otherwise obtained melting points in Table 1, the equations describing the melting equilibria for each polymorph can be obtained:

$$
\begin{aligned}
& P_{\text {I-liq }}(/ \mathrm{MPa})=5.57 T_{\text {I-liq }}(/ \mathrm{K})-2355 \\
& P_{\text {II-liq }}(/ \mathrm{MPa})=4.38 T_{\text {II-liq }}(/ \mathrm{K})-1815 \\
& P_{\text {III-liq }}(/ \mathrm{MPa})=4.29 T_{\text {III-liq }}(/ \mathrm{K})-1770
\end{aligned}
$$

The pressure of each melting point (at ordinary pressure) can be safely written as $0 \mathrm{MPa}$, because the equilibrium lines are very steep relative to the pressure and the error over the values of the vapor pressures, which themselves are in the order of pascal, by taking $0 \mathrm{MPa}$ 
will be negligible. Setting eqs. 2 and 3 equal leads to triple point I-II-liq, eqs. 2 and 4 lead to I-III-liq, and eqs. 3 and 4 lead to II-III-liq. The pressure and temperature coordinates can be found in Table 2 and their schematic positions are given in Figures 2A and B.

Table 2. Coordinates of triple points I-II-liq, I-III-liq, II-III-liq, and I-II-III derived from the data provided in Table 1

\begin{tabular}{cccc}
\hline Triple point & P /MPa & T/K & $\begin{array}{c}\text { Position in Figures } \\
\text { 2A and 2B }\end{array}$ \\
I-II-liq & 170 & 453 & Point 6 \\
I-III-liq & 195 & 458 & Point 7 \\
II-III-liq & 457 & 518 & Point 8 \\
I-II-III & -84 & 320 & Point 9 \\
\hline
\end{tabular}

\section{2.- Triple point I-II-III and equilibrium curve II-III obtained by triple points}

The triple point I-II-III only involves solid phases. In the same way as for the solidliquid equilibria, the expressions for the equilibrium curves I-II and I-III, intersecting in I-IIIII, can be obtained using the data in Table 1:

$$
\begin{aligned}
& P_{\text {I-II }}(/ \mathrm{MPa})=2.08 T(/ \mathrm{K})-749 \\
& P_{\text {I-III }}(/ \mathrm{MPa})=1.67 T(/ \mathrm{K})-618
\end{aligned}
$$

Setting eqs. 5 and 6 equal leads to the $(\mathrm{P}, \mathrm{T})$ coordinates of the I-II-III triple point of $320 \mathrm{~K}$ and -84 MPa. The values have been compiled in Table 2 together with the data on the triple points containing the melt. Schematically, the triple point has been placed in Figure 2B as well.

It can be observed that the I-II-III triple point is located in the negative-pressure or expanded-phase domain, i.e. the triple point I-II-III must be metastable (Table 2, Figure 2B). Considering the data in Table 1, this is not surprising as the slope of equilibrium II $\rightarrow$ I from its transition temperature of about $90^{\circ} \mathrm{C}$ is steeper with $2.08 \mathrm{MPa} \mathrm{K}^{-1}$ than the slope of equilibrium III $\rightarrow$ I with 1.67, which has a transition temperature that is located at a higher temperature of about $100{ }^{\circ} \mathrm{C}$. This can only mean that the two equilibria diverge with increasing pressure and that the triple point involving these solid phases must be located at 
negative pressure (see curve a and b in Figure 2B). However, this finding is inconsistent with the phase diagram in Figure 1, where the I-II-III triple point is located at positive pressure.

The II-III equilibrium calculated above with approximate experimental values leading to a slope of $0.48 \mathrm{MPa} \mathrm{K}^{-1}$, and which would confirm a negative triple point if it indeed occurs at $127^{\circ} \mathrm{C}$, can also be calculated using two triple points through which the equilibrium must pass, I-II-III and II-III-liq. It results in the following expression:

$$
P_{\text {II-III }}(/ \mathrm{MPa})=2.71 T(/ \mathrm{K})-952
$$

The slope of this equilibrium (line $\mathrm{c}$ in Figure 2B) is higher than both other solid-solid transitions in accordance with the proposed phase diagram in Figure 1, however, which of the two slopes for the II-III equilibrium should be considered the right one? It can also be seen that the sequence $T_{\mathrm{II} \rightarrow \mathrm{I}}<T_{\mathrm{III} \rightarrow \mathrm{I}}<T_{\mathrm{III} \rightarrow \mathrm{II}}$ as found for Figure 1 in the introduction does not hold anymore and has become $T_{\mathrm{III} \rightarrow \mathrm{II}}<T_{\mathrm{II} \rightarrow \mathrm{I}}<T_{\mathrm{III} \rightarrow \mathrm{I}}$ in Figure 2B. The strength of the topological method resides in consistency in the calculated triple points and phase equilibria, which unfortunately is lacking in this case.

\section{3.- Equilibrium I-III and its triple point I-III-liq}

The phase diagram in Figure 2B, which has been constructed with the data in Table 1 and the equations $2-7$ derived therefrom, highlights another problem as well. It can be seen that the I-III equilibrium (line b), which is defined by eq. 6 obtained by experimental data, cannot intersect its triple point in point $\mathbf{k}$ in Figure 2B (point 7 in Figure 2A). This is once again an inconsistency making it impossible to construct a thermodynamically consistent phase diagram.

\section{4.- Discussion}

Comparing the topological phase diagram constructed in the present paper using the data from Table 1 in Figure 2B with the one obtained in the original paper [1] (in the present text in Figure 2A), it can be seen that they are not the same. The experimental data compiled in Table 1 do not give rise to a positive pressure for the triple point I-II-III. The inconsistency is mentioned in the original paper on page 171 [1]: "As seen on the phase diagram, since the II-I equilibrium line passes through points 5 and 6 and the III-I equilibrium line through points 4 and 7, the slope of the II-I equilibrium line is necessary lower than that of the III-I equilibrium one. According to the calculated slopes (table 7), this should have been the 
opposite, although very close values. But the calculation gives the slope at the origin with the approximation that the two-phase equilibrium curve is treated as a straight line. This is not completely true and may explain the disagreement between the calculation and the thermodynamic construction."

Although the remark may appear innocent enough that a slight adjustment of a small difference in the slope may explain and solve the inconsistency, it does in fact invalidate either the experimental results or thermodynamics itself. It may be possible that the experimental error allows the inversion of the slopes, but in that case the data will need to be improved before constructing the phase diagram, as the data are not conclusive. If however, the data and therefore the slopes are correct, the reasoning in the quotation above would imply that the equilibria II-I and III-I cross each other twice, once at negative and once at positive pressure. This was already excluded by Riecke in 1890, who limited the number of triple points in a phase diagram to one per possible triplet (i.e. I-II-III, I-II-liq, etc.) [13], because two-phase equilibria are monotonically rising or descending curves that can therefore only cross once, as required by thermodynamics [2]. In addition, from our experience, experimentally obtained solid-solid and even solid-liquid equilibria are in fact straight lines over considerable pressure and temperature ranges, for example piracetam [14], cysteamine hydrochloride [15], and benzocaine [16] and many others [5-11,17-32]. The strength of the topological approach lies in the consistency of the results from different approaches. When there is no consistency in a topological phase diagram, the thermodynamic basis for that phase diagram vanishes. 

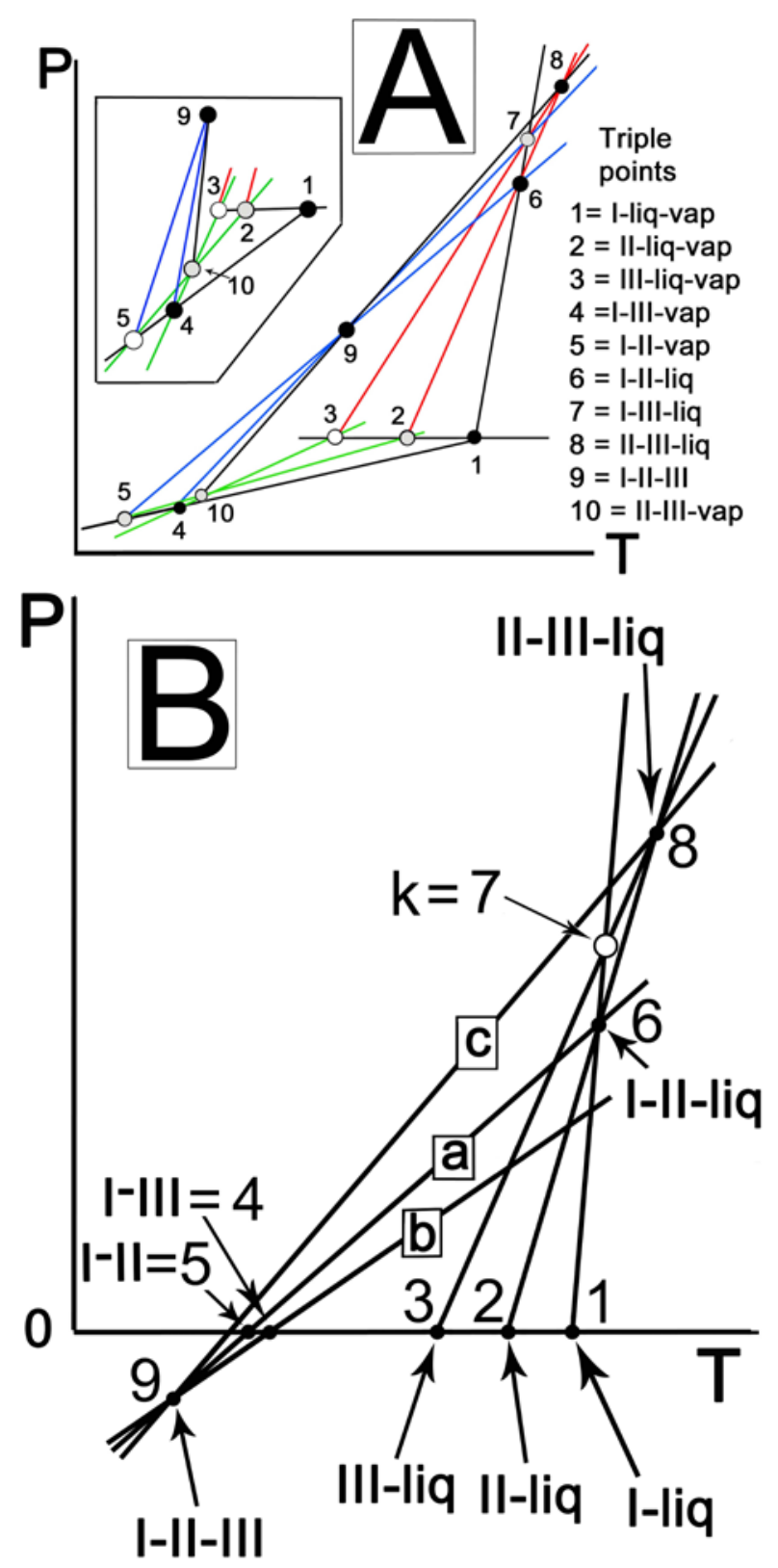

Figure 2. (A). The topological P-T phase diagram redrawn after the one presented in Figure 3 of reference [1]. The triple points have been numbered as indicated in the original figure. The equilibrium curves can be found through the triple points they cross, 5-9-6: I-II, 4-9-7: I-III, 10-9-8: II-III. The stability hierarchy of the equilibria has not been indicated. (B). The pressure-temperature phase diagram of piracetam with the two-phase equilibria obtained with the data in Table 1. The solid-solid equilibria are marked by letters a: I-II (slope $2.08 \mathrm{MPa} \mathrm{K}^{-}$ ${ }^{1}$ ), b: I-III (1.67 MPa K ${ }^{-1}$ ), and c: II-III (2.71 MPa K $\left.{ }^{-1}\right)$. In addition, the solid-liquid equilibria I-liq (5.57 MPa K${ }^{-1}$ ), II-liq (4.38 MPa K${ }^{-1}$ ), and III-liq (4.29 MPa $\mathrm{K}^{-1}$ ) are represented. Point $\mathbf{k}$ is the intersection of I-liq and III-liq, which ought to coincide with the triple point I-III-liq (point 7 in Figure 2A), implying that I-III (line b) must pass through this point; this is not possible with the data from Table 1. 


\section{Concluding remarks}

Topological phase diagrams do not necessarily provide an accurate description of the position of triple points and of two-phase equilibria. In fact, those positions are as accurate as experimental data and extrapolations can cause them to be. Nonetheless, the phase behavior and in particular the stability hierarchy of the phases involved can be accurately reproduced in a topological phase diagram. This may seem contradictive, but it implies that the overall position of the stability domains of the different phases relative to each other can be accurately determined. To ensure the accurate positioning of stable phase domains, the consistency within a topological phase diagram needs to be verified.

In the present paper, a number of feedback systems for the construction of topological phase diagrams has been highlighted. Thermodynamic cycles for state functions such as enthalpy and specific volume allow for example the determination of missing enthalpy changes between phases as demonstrated above. Moreover, hierarchies within the phase diagram must remain consistent, for example the hierarchy of the slopes of the different transitions $\mathrm{d} P / \mathrm{d} T_{\text {I-III }}<\mathrm{d} P / \mathrm{d} T_{\text {I-II }}<\mathrm{d} P / \mathrm{d} T_{\text {II-III, }}$ which is implied by the monotonicity of the equilibrium curves [2], but as well for experimental data such as $T_{\text {II-III }}<T_{\text {I-II }}<T_{\text {I-III }}$ and $\Delta H_{\mathrm{III} \rightarrow \mathrm{II}}<\Delta H_{\mathrm{II} \rightarrow \mathrm{I}}<\Delta H_{\mathrm{III} \rightarrow \mathrm{I}}$. The consistency of the measurement data may be obvious, but it does function as a feedback system, when extrapolations lead to other results. What to do when feedback fails to confirm consistency depends on each individual case, but a first reflex should be a thorough review of the experimental data.

\section{Acknowledgements}

This work was partially supported by the Spanish Ministry of Science and Innovation through the project FIS2014-54734-P and by the Generalitat de Catalunya under the project 2014 SGR-581.

\section{Appendix}

Estimation of the enthalpy changes from the DSC curves reported in Figure 1 of reference [1] by weighing the peaks or measuring their areas as triangles, both results related to the area of peak A (the melting peak of Form I) taken equal to $100 \%$ of $187 \mathrm{~J} / \mathrm{g}$.

The method leads to results similar to those provided in reference [1], even if slightly less accurate. 


\begin{tabular}{ccc}
\hline Transition & Value from [1] & Present estimate \\
\hline $\mathrm{II} \rightarrow \mathrm{I}$ & $24.8 \mathrm{~J} / \mathrm{g}$ & $20.8 \mathrm{~J} / \mathrm{g}$ \\
$\mathrm{III} \rightarrow \mathrm{I}$ & $26.8 \mathrm{~J} / \mathrm{g}$ & $24.5 \mathrm{~J} / \mathrm{g}$ \\
$\mathrm{III} \rightarrow \mathrm{II}^{*}$ & $+2 \mathrm{~J} / \mathrm{g}^{*}$ & $+3.7 \mathrm{~J} / \mathrm{g}^{*}$
\end{tabular}

* Since this transition is not observed, its enthalpy can be calculated from experimental data with $\Delta H_{\mathrm{III} \rightarrow \mathrm{I}}+\Delta H_{\mathrm{I} \rightarrow \mathrm{II}}+\Delta H_{\mathrm{II} \rightarrow \mathrm{III}}=0$.

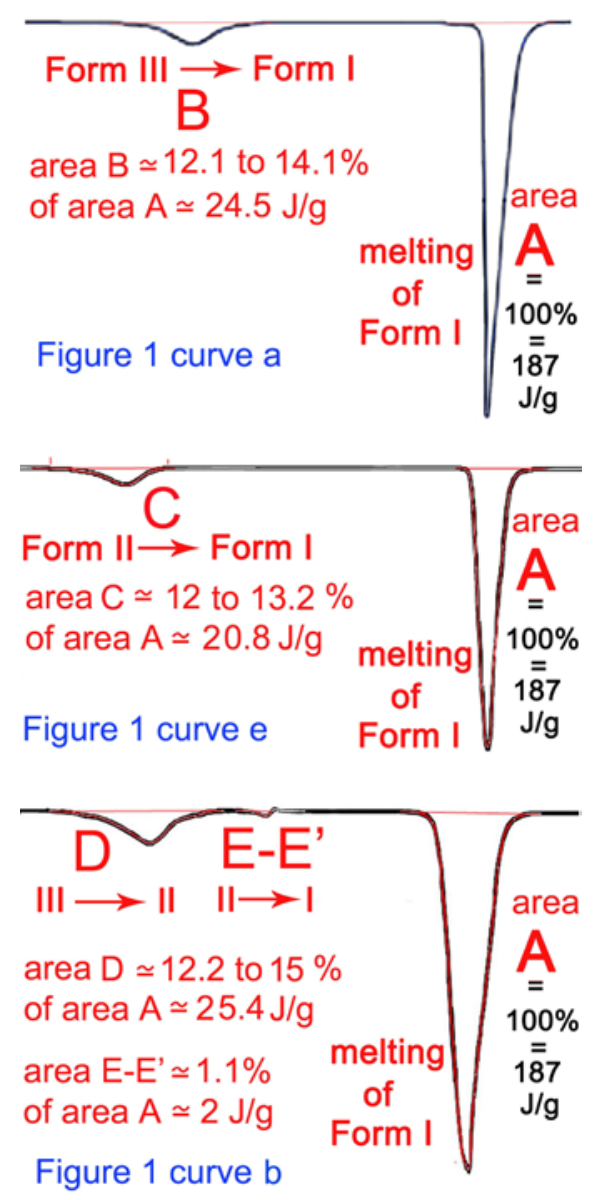

Figure A.1. Annotated differential scanning calorimetry curves for piracetam form III on heating following Figure 1 from reference [1].

\section{References}

1. Y. Corvis, A. Spasojevic-de Biré, C. Alzina, N. Guiblin, and P. Espeau, J. Chem. Thermodyn. 97, 167 (2016).

2. R. Céolin and I. B. Rietveld, Eur. Phys. J. - S.T. (2017). 
3. P. Espeau, R. Céolin, J. Ll. Tamarit, M. A. Perrin, J. P. Gauchi, and F. Leveiller, J. Pharm. Sci. 94 (3), 524 (2005).

4. J. Ledru, C. T. Imrie, C. R. Pulham, R. Céolin, and J. M. Hutchinson, J. Pharm. Sci. 96 (10), 2784 (2007).

5. P. Negrier, M. Barrio, J. Ll. Tamarit, and D. Mondieig, The Journal of Physical Chemistry B 118 (32), 9595 (2014).

6. B. B. Hassine, P. Negrier, M. Barrio, D. Mondieig, S. Massip, and J. Ll. Tamarit, Cryst Growth Des 15 (8), 4149 (2015).

7. P. Negrier, M. Barrio, M. Romanini, J. Ll. Tamarit, D. Mondieig, A. I. Krivchikov, L. Kepinski, A. Jezowski, and D. Szewczyk, Cryst Growth Des 14 (5), 2626 (2014).

8. J. L. Tamarit, M. Barrio, L. C. Pardo, P. Negrier, and D. Mondieig, J. Phys.: Condens. Matter 20 (24), 244110 (2008).

9. P. Negrier, M. Barrio, J. Ll. Tamarit, N. Veglio, and D. Mondieig, Cryst Growth Des 10 (6), 2793 (2010).

10. B. Parat, L. C. Pardo, M. Barrio, J. L. Tamarit, P. Negrier, J. Salud, D. O. López, and D. Mondieig, Chem. Mater. 17 (13), 3359 (2005).

11. M. Barrio, J. Ll. Tamarit, P. Negrier, L. C. Pardo, N. Veglio, and D. Mondieig, New J. Chem. 32 (2), 232 (2008).

12. S. Toscani, P. de Oliveira, and R. Céolin, J. Solid State Chem. 164 (1), 131 (2002).

13. E. Riecke, Z. Phys. Chem. (Munich) 6, 411 (1890).

14. S. Toscani, R. Céolin, L. Ter Minassian, M. Barrio, N. Veglio, J.-Ll. Tamarit, D. Louër, and I. B. Rietveld, Int. J. Pharm. 497, 96 (2016).

15. I. Gana, M. Barrio, C. Ghaddar, B. Nicolai, B. Do, J. L. Tamarit, F. Safta, and I. B. Rietveld, Mol Pharmaceut 12, 2276 (2015).

16. I. Gana, M. Barrio, B. Do, J.-L. Tamarit, R. Céolin, and I. B. Rietveld, Int. J. Pharm. 456 (2), 480 (2013).

17. B. Robert, M.-A. Perrin, M. Barrio, J.-Ll. Tamarit, G. Coquerel, R. Céolin, and I. B. Rietveld, J. Pharm. Sci. 105, 64 (2016).

18. M.-A. Perrin, M. Bauer, M. Barrio, J.-Ll. Tamarit, R. Céolin, and I. B. Rietveld, J. Pharm. Sci. 102 (7), 2311 (2013).

19. I. B. Rietveld, M.-A. Perrin, S. Toscani, M. Barrio, B. Nicolaï, J.-Ll. Tamarit, and R. Céolin, Mol Pharmaceut 10 (4), 1332 (2013).

20. I. B. Rietveld, M. Barrio, B. Do, J.-Ll. Tamarit, and R. Céolin, J. Phys. Chem. B 116 (18), 5568 (2012).

21. M. Barrio, E. Maccaroni, I. B. Rietveld, L. Malpezzi, N. Masciocchi, R. Céolin, and J.Ll. Tamarit, J. Pharm. Sci. 101 (3), 1073 (2012).

22. I. B. Rietveld, M. Barrio, J.-Ll. Tamarit, B. Do, and R. Céolin, J. Phys. Chem. B 115 (49), 14698 (2011).

23. R. Levit, M. Barrio, N. Veglio, J. Ll. Tamarit, P. Negrier, L. C. Pardo, J. SanchezMarcos, and D. Mondieig, J. Phys. Chem. B 112 (44), 13916 (2008).

24. N. Mahé, M. Perrin, M. Barrio, B. Nicolaï, I. Rietveld, J. Ll. Tamarit, and R. Céolin, J. Pharm. Sci. 100 (6), 2258 (2011).

25. R. Céolin, M. Barrio, J. Ll. Tamarit, N. Veglio, M. A. Perrin, and P. Espeau, J. Pharm. Sci. 99 (6), 2756 (2010).

26. M. Barrio, P. Espeau, J. Ll. Tamarit, M. A. Perrin, N. Veglio, and R. Céolin, J. Pharm. Sci. 98 (5), 1657 (2009).

27. R. Céolin, J. Ll. Tamarit, M. Barrio, D. O. Lopez, B. Nicolaï, N. Veglio, M. A. Perrin, and P. Espeau, J. Pharm. Sci. 97 (9), 3927 (2008). 
28. P. Negrier, L. C. Pardo, J. Salud, J. Ll. Tamarit, M. Barrio, D. O. Lopez, A. Würflinger, and D. Mondieig, Chem. Mater. 14 (5), 1921 (2002).

29. M. Barrio, P. de Oliveira, R. Céolin, D. O. Lopez, and J. L. Tamarit, Chem. Mater. 14 (2), 851 (2002).

30. J. Reuter, D. Büsing, J. Ll. Tamarit, and A. Würflinger, J. Mater. Chem. 7 (1), 41 (1997).

31. P. Lloveras, E. Stern-Taulats, M. Barrio, J.-Ll. Tamarit, S. Crossley, W. Li, V. Pomjakushin, A. Planes, L. Mañosa, and N. Mathur, Nature Comm. 6 (2015).

32. J. Ll. Tamarit, B. Legendre, and J. Buisine, Mol. Cryst. Liq. Cryst. 250 (1), 347 (1994). 